Check for updates

Cite this: RSC Adv., 2019, 9, 11894

Received 23rd December 2018

Accepted 4th April 2019

DOI: $10.1039 / c 8 r a 10524 c$

rsc.li/rsc-advances

\section{Preparation of mesoporous $\mathrm{ZnAl}_{2} \mathrm{O}_{4}$ nanoflakes by ion exchange from a $\mathrm{Na}$-dawsonite parent material in the presence of an ionic liquid $\dagger$}

\author{
Tongll Kim, (D) ab HakSung Yun, ${ }^{a}$ GwangBok Han, ${ }^{a}$ Jiabiao Lian, ${ }^{\text {bc }}$ Jianmin Ma, (D) bd \\ Xiaochuan Duan, (D) be Lianjie Zhu*f and Wenjun Zheng (DD *b
}

\begin{abstract}
Herein, mesoporous $\mathrm{ZnAl}_{2} \mathrm{O}_{4}$ spinel nanoflakes were prepared by an ion-exchange method from a $\mathrm{Na}$ dawsonite parent material in the presence of an ionic liquid, 1-butyl-2,3-dimethylimidazolium chloride ([bdmim] [Cl]), followed by calcination at $700{ }^{\circ} \mathrm{C}$ for $2 \mathrm{~h}$. The as-obtained products were characterized by several techniques such as X-ray diffraction (XRD), Fourier transform infrared (FTIR) spectroscopy, thermogravimetric analysis (TGA), scanning electron microscopy (SEM), transmission electron microscopy (TEM), and energy dispersive $\mathrm{X}$-ray spectroscopy (EDX). The $\mathrm{ZnAl}_{2} \mathrm{O}_{4}$ nanoflakes with the thickness of $\sim 20 \mathrm{~nm}$ were composed of numerous nanoparticles, which resulted in a high specific surface area of $245 \mathrm{~m}^{2} \mathrm{~g}^{-1}$. The formation mechanism of the $\mathrm{ZnAl}_{2} \mathrm{O}_{4}$ nanoflakes was comprehensively investigated, and the results showed that a $2 \mathrm{D}$ growth process of the $\mathrm{Zn}_{6} \mathrm{Al}_{2}(\mathrm{OH})_{16}\left(\mathrm{CO}_{3}\right) \cdot 4 \mathrm{H}_{2} \mathrm{O}$ crystallites with the assistance of $[\mathrm{bdmim}][\mathrm{Cl}]$ was the key for the induction of $\mathrm{ZnAl}_{2} \mathrm{O}_{4}$ nanoflakes. Moreover, mesopores were formed between adjacent nanoparticles due to the release of $\mathrm{CO}_{2}$ and $\mathrm{H}_{2} \mathrm{O}$ molecules from $\mathrm{Zn}_{6} \mathrm{Al}_{2}(\mathrm{OH})_{16}\left(\mathrm{CO}_{3}\right) \cdot 4 \mathrm{H}_{2} \mathrm{O}$ during the calcination process.
\end{abstract}

\section{Introduction}

Zinc aluminate $\left(\mathrm{ZnAl}_{2} \mathrm{O}_{4}\right)$ spinel is a well-known wide band gap semiconductor $\left(E_{\mathrm{g}}=3.8 \mathrm{eV}\right)^{\mathbf{1}}$ ceramic material with optomechanical property, which has been extensively studied as a catalyst and catalyst support, ${ }^{2-4}$ transparent conductor, ${ }^{5}$ dielectric material, ${ }^{6}$ optical material ${ }^{7}$ and sensor ${ }^{8}$ due to its high thermal stability, low surface acidity and high mechanical resistance. ${ }^{9}$ Several methods, for example, the solid statereaction or ceramic method, ${ }^{\mathbf{1 0}}$ wet chemical routes, ${ }^{\mathbf{1 1}, 12}$ the sol-gel method, ${ }^{\mathbf{1 3 4}}$ the hydrothermal method, ${ }^{\mathbf{1 5}}$ the solvothermal method, ${ }^{\mathbf{1 6}}$ the plasma method, ${ }^{17}$ combustion in an aqueous solution ${ }^{18}$ and molten salt synthesis ${ }^{19}$ etc., have been applied for the preparation of $\mathrm{ZnAl}_{2} \mathrm{O}_{4}$ spinel. However, to date,

anstitute of Chemistry and Biology, University of Science, Unjong District, Pyongyang, D. P. R. Korea

${ }^{b}$ Department of Materials Chemistry, Key Laboratory of Advanced Energy Materials Chemistry, TKL of Metal and Molecule-Baced Material Chemistry, College of Chemistry, Nankai University Tianjin, 300071, P. R. China. E-mail: zhwj@nankai. edu.cn

'Institute for Energy Research, Jiangsu University, Zhenjiang 212013, P. R. China

${ }^{d}$ School of Physics and Electronics, Hunan University, Changsha 410082, P. R. China ${ }^{e}$ Pen-Tung Sah Institute of Micro-Nano Science and Technology of Xiamen University, Xiamen, 361005, P. R. China

${ }^{f}$ School of Chemistry \& Chemical Engineering, Tianjin University of Technology, Tianjin 300384, P. R. China. E-mail: zhulj@tjut.edu.cn

$\dagger$ Electronic supplementary information (ESI) available. See DOI: $10.1039 / \mathrm{c} 8 \mathrm{ra} 10524 \mathrm{c}$ it is still a challenge to synthesize $2 \mathrm{D}$ or $3 \mathrm{D} \mathrm{ZnAl}_{2} \mathrm{O}_{4}$ spinel nanostructures via a solution route. Although hierarchical $\mathrm{ZnO}-$ $\mathrm{Al}_{2} \mathrm{O}_{3}$ microspheres have been reported, ${ }^{\mathbf{2 0 , 2 1}}$ to date, the pure phase of $2 \mathrm{D} \mathrm{ZnAl}_{2} \mathrm{O}_{4}$ nanoflakes has not been prepared via a facile ion-exchange method.

Dawsonite (denoted by Na-Dw) is a mineralogical nomenclature that specifically refers to the naturally formed sodium hydroxyalumino-carbonate, $\operatorname{NaAl}\left(\mathrm{CO}_{3}\right)(\mathrm{OH})_{2} \cdot{ }^{22}$ The Na-Dw compounds have been applied as ingredients in antacids, ${ }^{23}$ stabilizers in polymers, ${ }^{\mathbf{2 4 , 2 5}}$ dry extinguishers in fuel leak fires, ${ }^{26}$ additives in synthetic fertilizers ${ }^{27}$ and precursors for pure alumina. . $^{28-30}$

Recently, the advantages of ionic liquids (ILs) have been gradually discovered in the synthetic processes of inorganic nanomaterials. ${ }^{31-37}$ Particularly, ILs have received significant attention as templates in the synthesis of numerous functional materials. Our research group has successfully synthesized various functional nanostructures using ionic liquids as soft templates, reactants or precursors. ${ }^{38-42}$

Herein, we present mesoporous $\mathrm{ZnAl}_{2} \mathrm{O}_{4}$ nanoflakes prepared by the ion-exchange method from a Na-Dw parent material in the presence of an ionic liquid, [bdmim] [Cl], followed by calcination at $700{ }^{\circ} \mathrm{C}$ for $2 \mathrm{~h}$. The product exhibits a thin flake-like morphology, composed of numerous nanoparticles, and has a high specific surface area, $245 \mathrm{~m}^{2} \mathrm{~g}^{-1}$. To the best of our knowledge, this is the first time that $\mathrm{ZnAl}_{2} \mathrm{O}_{4}$ spinel nanoflakes have been prepared by the ion-exchange method from a Na-Dw parent material. 


\section{Experimental}

All the reagents were of analytical grade and used without further purification. The ionic liquid 1-butyl-2,3dimethylimidazolium chloride ([bdmim][Cl]) was purchased from Lanzhou Greenchem ILS (LICP, CAS, China).

\subsection{Synthesis of the Na-Dw parent material}

The Na-Dw parent material was prepared by the coprecipitation method reported in the literature. ${ }^{43}$ Typically, $2 \mathrm{mmol}$ of $\mathrm{AlCl}_{3} \cdot 6 \mathrm{H}_{2} \mathrm{O}$ was dissolved in $15 \mathrm{~mL}$ of deionized water under constant stirring, and then, $10 \mathrm{mmol}$ of $\mathrm{NaHCO}_{3}$ was slowly added to the solution at room temperature. The obtained gel was hydrothermally treated at $120^{\circ} \mathrm{C}$ for $12 \mathrm{~h}$ in a $20 \mathrm{~mL}$ Teflonlined stainless steel autoclave. After the reaction was completed, the autoclave was naturally cooled down to room temperature. Then, the slurry was centrifuged and washed several times with distilled water and ethanol. The white solid residues were dried at $80{ }^{\circ} \mathrm{C}$ for $2 \mathrm{~h}$, and thus, the Na-Dw parent material was obtained.

\subsection{Synthesis of the $\mathrm{ZnAl}_{2} \mathrm{O}_{4}$ nanoflakes}

In a typical preparation of $\mathrm{ZnAl}_{2} \mathrm{O}_{4}, 0.6 \mathrm{mmol}(0.1 \mathrm{~g})$ of Na-Dw and $1 \mathrm{mmol}$ of the ionic liquid [bdmim][Cl] were added to $10 \mathrm{~mL}$ of $0.03 \mathrm{M} \mathrm{Zn}\left(\mathrm{NO}_{3}\right)_{2}$ aqueous solution, and then, the mixture was slowly stirred and maintained at $50{ }^{\circ} \mathrm{C}$ for $10 \mathrm{~h}$. The as-obtained white precipitate was centrifuged, washed several times with distilled water and ethanol, dried at $80{ }^{\circ} \mathrm{C}$ for $2 \mathrm{~h}$, and finally calcined at $700{ }^{\circ} \mathrm{C}$ for $2 \mathrm{~h}$ to obtain the $\mathrm{ZnAl}_{2} \mathrm{O}_{4}$ nanoflakes.

\subsection{Characterizations}

The products were characterized by XRD, FTIR spectroscopy, SEM, TEM and EDX. XRD measurements were performed using the Rigaku $\mathrm{D} / \max 2500$ diffractometer with $\mathrm{Cu} \mathrm{K} \alpha$ radiation $(\lambda=$ $0.154056 \mathrm{~nm}$ ) at $V=40 \mathrm{kV}$ and $I=150 \mathrm{~mA}$, and the scanning speed was $8^{\circ} \mathrm{min}^{-1}$. TGA measurements were performed using the DuPont Instruments 951 Thermogravimetric analyzer from room temperature to $725{ }^{\circ} \mathrm{C}$ in flowing nitrogen gas at the heating rate of $5^{\circ} \mathrm{C} \mathrm{min}^{-1}$. The FTIR spectroscopy of the sample was conducted at room temperature with a $\mathrm{KBr}$ pellet using the VECTOR-22 (Bruker) spectrometer in the range from 400 to $4000 \mathrm{~cm}^{-1}$. The morphologies of the samples were studied by field emission scanning electron microscopy (FE-SEM, JEOL JSM-6700F). The TEM and HR-TEM images and EDX spectra were obtained using the Tecnai G2 20S-Twin transmission electron microscope operating at the accelerating voltage of 120 $\mathrm{kV}$. The specific surface areas $\left(S_{\mathrm{BET}}\right)$ of the samples were calculated by following the multipoint Brunauer-EmmettTeller (BET) procedure using the Quantachrome Nova 2000e sorption analyzer. The pore diameter and the pore size distribution were determined by the Barrett-Joyner-Halenda (BJH) method.

\section{Results and discussions}

Fig. 1a shows the XRD pattern of the Na-Dw parent material prepared at $120{ }^{\circ} \mathrm{C}$ in $12 \mathrm{~h}$. All detectable peaks in this pattern can be assigned by their peak positions to orthorhombic $\mathrm{NaAl}\left(\mathrm{CO}_{3}\right)(\mathrm{OH})_{2}$ (JCPDS: 45-1359). No evidence could be found for the existence of other impurities in the product after washing. The XRD pattern of the precursor prepared by ion exchange using the $\mathrm{Zn}\left(\mathrm{NO}_{3}\right)_{2}$ solution is shown in Fig. 1b, which clearly shows two types of characteristic diffraction peaks that can be indexed to monoclinic $\mathrm{Al}_{2} \mathrm{O}_{3} \cdot 3 \mathrm{H}_{2} \mathrm{O}$ (JCPDS: 01-0259) and hexagonal $\mathrm{Zn}_{6} \mathrm{Al}_{2}(\mathrm{OH})_{16}\left(\mathrm{CO}_{3}\right) \cdot 4 \mathrm{H}_{2} \mathrm{O}$ (JCPDS: 38-0486). The XRD patterns of the samples obtained after calcination of the precursor at 500 and $700{ }^{\circ} \mathrm{C}$ for $2 \mathrm{~h}$ (Fig. 1c and d), respectively, present the characteristic diffraction peaks of the cubic phase $\mathrm{ZnAl}_{2} \mathrm{O}_{4}$ spinel (JCPDS: 05-0669); they indicate that the mixed crystalline phases of the precursor have been converted to the pure $\mathrm{ZnAl}_{2} \mathrm{O}_{4}$ spinel crystalline phase upon heat treatment, and higher calcination temperature is beneficial for the enhancement of crystallinity. As is well-known, the average size of the nanocrystal can be calculated via the Scherrer formula: ${ }^{44}$

$$
D_{h k l}=K \lambda /\left(\beta_{h k l} \cos \theta_{h k l}\right)
$$

where $D_{h k l}$ is the particle size perpendicular to the normal line of the $(h k l)$ plane, $K$ is a constant (it is 0.9$), h k l$ is the full width at half-maximum of the $(h k l)$ diffraction peak, $\theta_{h k l}$ is the diffraction angle, and $\lambda$ is the wavelength of $\mathrm{X}$-ray. The average size of the $\mathrm{ZnAl}_{2} \mathrm{O}_{4}$ spinel nanocrystal calculated from the strongest diffraction peak (311) shown in Fig. 1d is about $4.7 \mathrm{~nm}$. The lattice parameter of the crystal was calculated based on the $\mathrm{X}$ ray diffraction pattern using the following equation, ${ }^{\mathbf{4 4}}$

$$
a^{2}=d_{h k l^{2}}\left(h^{2}+k^{2}+l^{2}\right)
$$

where $a$ is the lattice parameter, $d_{h k l}$ is the interplanar spacing corresponding to the Miller indices, and $h, k, l$ are the miller indices. The calculated lattice parameter of the spinel $\mathrm{ZnAl}_{2} \mathrm{O}_{4}$ product (Fig. 1d) is $8.195 \AA$, which is very close to the theoretical value of gahnite $(8.0848 \AA)$. The abovementioned results are similar to those reported in previous studies. ${ }^{\mathbf{1 8 , 4 5}}$

The thermal stability of the precursor prepared by ion exchange at $50{ }^{\circ} \mathrm{C}$ in $10 \mathrm{~h}$ was investigated by TGA and DTG. As shown in Fig. 2, the precursor exhibits the total weight loss of about $36.6 \%$. Based on previous studies, ${ }^{\mathbf{4 6 - 4 9}}$ we believe that the thermal decomposition process includes five steps as follows: (1) a $7.2 \%$ weight loss from 30 to $110{ }^{\circ} \mathrm{C}$ due to the removal of physically adsorbed water and part of crystal water from $\mathrm{Al}_{2}$ $\mathrm{O}_{3} \cdot 3 \mathrm{H}_{2} \mathrm{O}$ (eqn (2)), (2) a $2.7 \%$ weight loss from 110 to $150{ }^{\circ} \mathrm{C}$ due to the phase transition from $\mathrm{Al}_{2} \mathrm{O}_{3} \cdot 3 \mathrm{H}_{2} \mathrm{O}$ to $\mathrm{AlOOH}$ (eqn (2)), (3) a $7.4 \%$ weight loss from 150 to $230{ }^{\circ} \mathrm{C}$, assigned to the removal of structural interlayer water of the $\mathrm{Zn}_{6} \mathrm{Al}_{2}(\mathrm{OH})_{16}\left(\mathrm{CO}_{3}\right) \cdot 4 \mathrm{H}_{2} \mathrm{O}$ crystals (eqn (3)), (4) a $16.1 \%$ weight loss from 230 to $500{ }^{\circ} \mathrm{C}$, attributed to the removal of residual crystal water, $\mathrm{CO}_{2}$ molecules and part of hydroxyl groups from the crystals of $\mathrm{AlOOH}$ and $\mathrm{Zn}_{6} \mathrm{Al}_{2}(\mathrm{OH})_{16}\left(\mathrm{CO}_{3}\right)$ (eqn (5) and (6)), and (5) a 3.2\% weight loss above $500{ }^{\circ} \mathrm{C}$ due to the removal of residual hydroxyl 


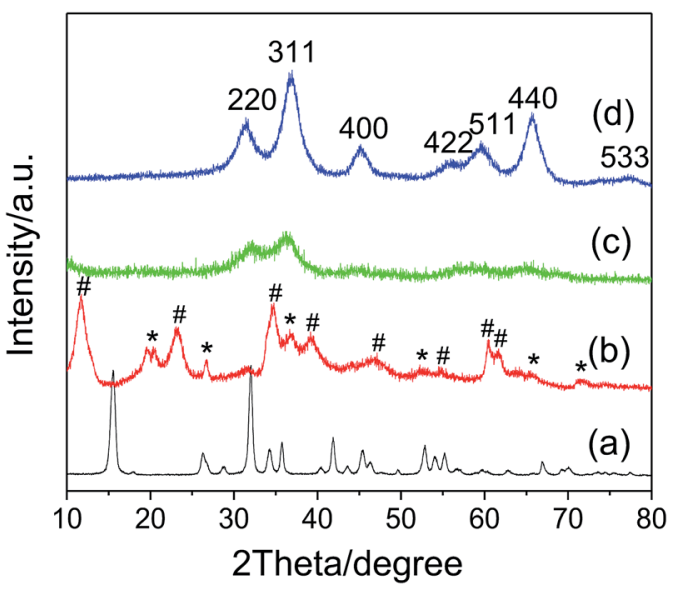

Fig. 1 XRD patterns of (a) the Na-Dw parent material prepared by a hydrothermal method at $120^{\circ} \mathrm{C}$ for $12 \mathrm{~h}$, (b) the precursor prepared by ion exchange at $50^{\circ} \mathrm{C}$ for $10 \mathrm{~h}$ from the $\mathrm{Na}$-Dw parent material, and (c and d) the samples obtained by calcination of the precursor at (c) $500{ }^{\circ} \mathrm{C}$ and (d) $700{ }^{\circ} \mathrm{C}$ for $2 \mathrm{~h}$, respectively. (\#) $\mathrm{Zn}_{6} \mathrm{Al}_{2}(\mathrm{OH})_{16}\left(\mathrm{CO}_{3}\right)$. $4 \mathrm{H}_{2} \mathrm{O}$ (JCPDS: 38-0486) and (*) $\mathrm{Al}_{2} \mathrm{O}_{3} \cdot 3 \mathrm{H}_{2} \mathrm{O}$ (JCPDS: 01-0259).

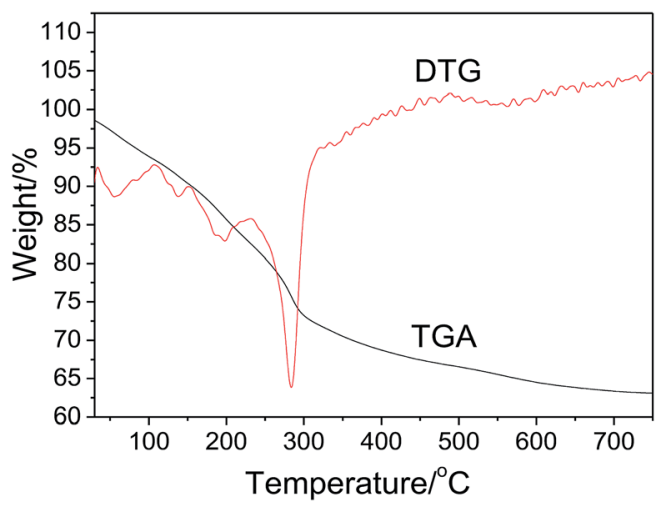

Fig. 2 TGA-DTG curves of the precursor prepared by ion exchange at $50{ }^{\circ} \mathrm{C}$ for $10 \mathrm{~h}$.

groups. Based on the TGA results, we proposed the formation process of the $\mathrm{ZnAl}_{2} \mathrm{O}_{4}$ nanoflakes as follows:

$$
\begin{aligned}
& 12 \mathrm{NaAl}(\mathrm{OH})_{2} \mathrm{CO}_{3}+6 \mathrm{Zn}^{2+}+\mathrm{H}_{2} \mathrm{O} \rightarrow 5 \mathrm{Al}_{2} \mathrm{O}_{3} \cdot 3 \mathrm{H}_{2} \mathrm{O} \\
& +\mathrm{Zn}_{6} \mathrm{Al}_{2}(\mathrm{OH})_{16}\left(\mathrm{CO}_{3}\right) \cdot 4 \mathrm{H}_{2} \mathrm{O}+12 \mathrm{Na}^{+}+11 \mathrm{CO}_{2} \\
& \mathrm{Al}_{2} \mathrm{O}_{3} \cdot 3 \mathrm{H}_{2} \mathrm{O} \rightarrow 2 \mathrm{AlOOH}+2 \mathrm{H}_{2} \mathrm{O}\left[\sim 150{ }^{\circ} \mathrm{C}: W_{\text {loss }}=11.1 \%\right](2) \\
& \mathrm{Zn}_{6} \mathrm{Al}_{2}(\mathrm{OH})_{16}\left(\mathrm{CO}_{3}\right) \cdot 4 \mathrm{H}_{2} \mathrm{O} \rightarrow \mathrm{Zn}_{6} \mathrm{Al}_{2}(\mathrm{OH})_{16}\left(\mathrm{CO}_{3}\right) \\
& +4 \mathrm{H}_{2} \mathrm{O}\left[150-230{ }^{\circ} \mathrm{C}: W_{\text {loss }}=4.5 \%\right](3) \\
& \mathrm{Zn}_{6} \mathrm{Al}_{2}(\mathrm{OH})_{16}\left(\mathrm{CO}_{3}\right) \rightarrow 6 \mathrm{ZnO}+\mathrm{Al}_{2} \mathrm{O}_{3}+8 \mathrm{H}_{2} \mathrm{O} \\
& +\mathrm{CO}_{2}\left[230-500{ }^{\circ} \mathrm{C}: W_{\text {loss }}=11.6 \%\right] \\
& 2 \mathrm{AlOOH} \rightarrow \mathrm{Al}_{2} \mathrm{O}_{3}+\mathrm{H}_{2} \mathrm{O}\left[230-500{ }^{\circ} \mathrm{C}: W_{\text {loss }}=5.6 \%\right] \\
& \mathrm{ZnO}+\mathrm{Al}_{2} \mathrm{O}_{3} \rightarrow \mathrm{ZnAl}_{2} \mathrm{O}_{4}
\end{aligned}
$$
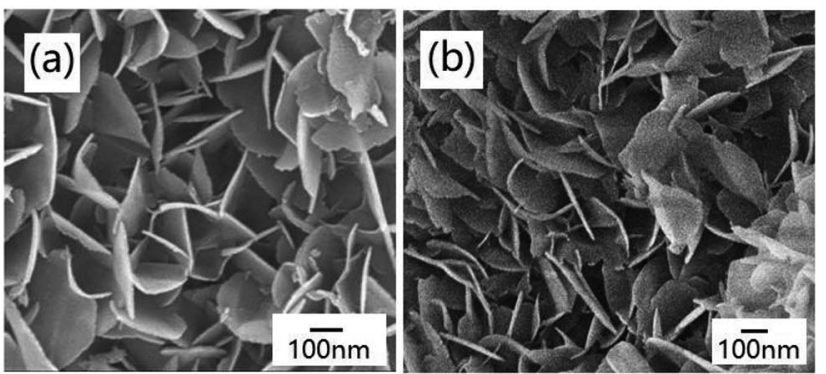

Fig. 3 FE-SEM images of the products obtained (a) before and (b) after calcination at $700{ }^{\circ} \mathrm{C}$ for $2 \mathrm{~h}$ decomposition process is $32.8 \%$, which is consistent with the TGA result.

The FTIR spectrum of the product obtained after calcination of the precursor at $700{ }^{\circ} \mathrm{C}$ for $2 \mathrm{~h}$ is shown in Fig. S1(a) in the ESI. $\dagger$ It displays a strong band around $3460 \mathrm{~cm}^{-1}$, which is attributed to the vibration of the $\mathrm{OH}$ group bonded to the surface. The band at $1610 \mathrm{~cm}^{-1}$ is associated with the vibration of $\mathrm{Al}-\mathrm{OH}$, characteristic of $\mathrm{ZnAl}_{2} \mathrm{O}_{4}$, and the weak peak at $1398 \mathrm{~cm}^{-1}$ is due to the $\mathrm{HOH}$ vibration of water. The wide band from 797 to $497 \mathrm{~cm}^{-1}$ is related to the inorganic network, including the $\mathrm{Zn}-\mathrm{O}$ bending vibrations, Al-O stretching vibrations and Al-O-Zn stretching vibrations. ${ }^{45,50,51}$ As shown in Fig. S1(b) in the ESI, $\dagger$ the local composition EDX spectrum reveals that the stoichiometric atom concentration ratio is $\mathrm{Zn}: \mathrm{Al}: \mathrm{O} \approx 15.6: 29.3: 55.1 \% \approx 1: 2: 4$, confirming that the as-obtained product is $\mathrm{ZnAl}_{2} \mathrm{O}_{4}$. Moreover, a Cu signal located at $8.1 \mathrm{eV}$ was revealed, which originated from a copper grid used in the HR-TEM measurement.

The morphologies of the products were characterized by FESEM. The FE-SEM image of Na-Dw is shown in Fig. S2 in the ESI, $\dagger$ which exhibits a nanorod shape. However, well-developed nanoflakes were obtained after $\mathrm{Zn}^{2+}$ ion exchange reactions in the presence of the ionic liquid (Fig. 3a). To clarify the effect of the ionic liquid [bdmim][Cl] on the morphology of the product, a control experiment was carried out in the absence of the ionic liquid, and other reaction conditions were kept constant. The FE-SEM image of the as-obtained product is shown in Fig. S3 in the ESI, $\uparrow$ which displays an irregular shape with few nanoflakes. These results imply that in the present reaction system, the ionic liquid has an important effect on the morphology of the product; moreover, ion exchange occurs between $\mathrm{Zn}^{2+}$ ions and Na-Dw molecules dissolved in solution, and then, new structures can be formed via recrystallization of the product molecules. There is no significant role of the ionic liquid in the ion exchange process, whereas in the crystal growth process, the ionic liquid plays a crucial role. Moreover, the abovementioned results reveal that the ILs can have an important effect on the morphologies of the inorganic materials at the very low temperature of about $50{ }^{\circ} \mathrm{C}$; in an IL-templated system, the nanostructures of inorganic materials are generated by a hydrogen bonding-co- $\pi-\pi$ stacking mechanism, as discussed in previous studies; ${ }^{\mathbf{4 0 - 4 2}}$ the morphology of the sample after
The theoretical total weight loss during the thermal- 
calcination at $700{ }^{\circ} \mathrm{C}$ for $2 \mathrm{~h}$ is well-preserved, and the sample still possesses a nanoflake shape (Fig. $3 \mathrm{~b}$ ).

Fig. 4 shows the TEM images of the product obtained by calcination at $700{ }^{\circ} \mathrm{C}$ for $2 \mathrm{~h}$, which display a nanoflake-like morphology, and each nanoflake is composed of numerous nanoparticles with the diameters of about $20 \mathrm{~nm}$. There are many mesopores between adjacent nanoparticles (Fig. $4 \mathrm{~b}$ ). The typical lattice spacing was determined to be $0.29 \mathrm{~nm}$, corresponding to the (220) lattice plane of $\mathrm{ZnAl}_{2} \mathrm{O}_{4}$ (inset in Fig. $4 \mathrm{~b}$ ).

The effect of the mole ratios of $\mathrm{Zn}^{2+}: \mathrm{Na}$-Dw on the crystal phase of the precursors was investigated on the basis of control experiments. As shown in Fig. 5, two crystal phases of $\mathrm{Al}_{2} \mathrm{O}_{3^{-}}$ $\cdot 3 \mathrm{H}_{2} \mathrm{O}$ and $\mathrm{Zn}_{6} \mathrm{Al}_{2}(\mathrm{OH})_{16}\left(\mathrm{CO}_{3}\right) \cdot 4 \mathrm{H}_{2} \mathrm{O}$ co-existed in the precursor when the mole ratio was $1: 2$. As the mole ratio of $\mathrm{Zn}^{2+}: \mathrm{Na}-\mathrm{Dw}$ was increased, the concentration of the $\mathrm{Zn}_{6} \mathrm{Al}_{2}(\mathrm{OH})_{16}\left(\mathrm{CO}_{3}\right)$. $4 \mathrm{H}_{2} \mathrm{O}$ phase gradually increased; when the mole ratio of $\mathrm{Zn}^{2+}$ : Na-Dw reached $3: 1$, pure phase of the $\mathrm{Zn}_{6} \mathrm{Al}_{2}(\mathrm{OH})_{16}(-$ $\left.\mathrm{CO}_{3}\right) \cdot 4 \mathrm{H}_{2} \mathrm{O}$ crystal was obtained. To further clarify the effect of the $\mathrm{Zn}^{2+}$ : Na-Dw mole ratio on the product structure, XRD analysis of the products obtained by calcination of the precursors at $700{ }^{\circ} \mathrm{C}$ for $2 \mathrm{~h}$ was carried out, as shown in Fig. $\mathrm{S} 4$ in the ESI. $\dagger$ When the mole ratio was $1: 2$, pure $\mathrm{ZnAl}_{2} \mathrm{O}_{4}$ crystals could be obtained. In other cases, however, $\mathrm{ZnO}$ and $\mathrm{ZnAl}_{2} \mathrm{O}_{4}$ coexisted in the products. Moreover, as the mole ratio increased, the $\mathrm{ZnO}$ phase became the main crystal phase of the product.
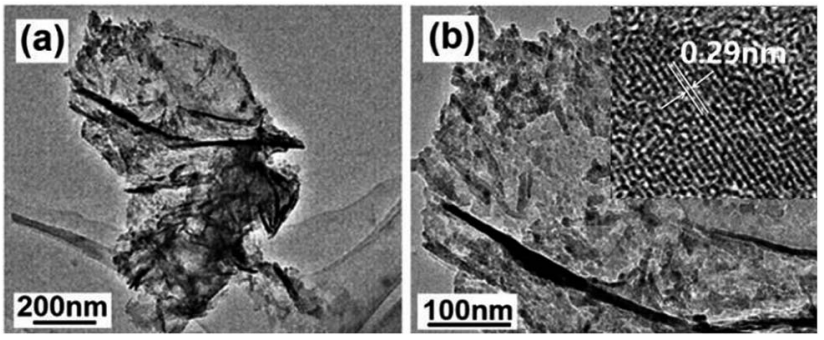

Fig. 4 (a) Low- and (b) high-magnification TEM images of the product obtained by calcination at $700{ }^{\circ} \mathrm{C}$ for $2 \mathrm{~h}$. Inset in (b) shows the HRTEM image.

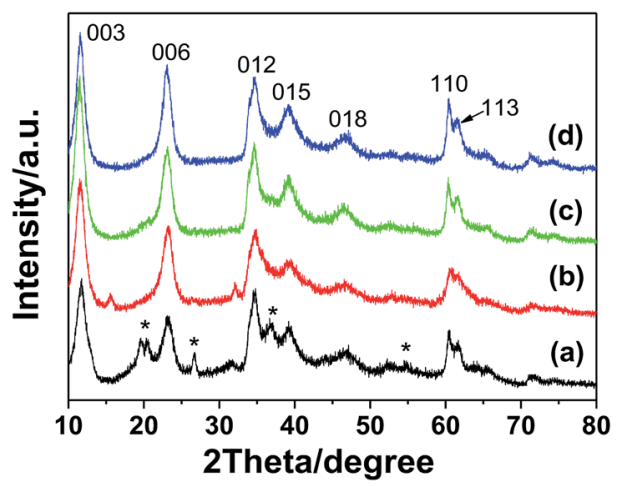

Fig. $5 \mathrm{XRD}$ patterns of the samples obtained by $\mathrm{Zn}^{2+}$ ion exchange reactions with different mole ratios of $\mathrm{Zn}^{2+}: \mathrm{Na}-\mathrm{Dw}$ : (a) $1: 2$, (b) $1: 1$, (c) $2: 1$ and (d) $3: 1$. '*' symbol represents $\mathrm{Al}_{2} \mathrm{O}_{3} \cdot 3 \mathrm{H}_{2} \mathrm{O}$ (JCPDS: 010259).
These results reveal that the mole ratio of $\mathrm{Zn}^{2+}:$ Na-Dw significantly influences the product composition, and the optimal mole ratio is $1: 2$ to obtain the pure phase of $\mathrm{ZnAl}_{2} \mathrm{O}_{4}$ nanoflakes. Fig. S5 in the ESI $\dagger$ shows the morphologies of the precursors obtained using $\mathrm{Zn}^{2+}: \mathrm{Na}-\mathrm{Dw}$ at different mole ratios. It can be observed that there are no significant changes in the morphology of the precursors with a change in the mole ratios; this indicates that the nanoflakes are formed from $\mathrm{Zn}_{6} \mathrm{Al}_{2}(-$ $\mathrm{OH})_{16}\left(\mathrm{CO}_{3}\right) \cdot 4 \mathrm{H}_{2} \mathrm{O}$ rather than from $\mathrm{Al}_{2} \mathrm{O}_{3} \cdot 3 \mathrm{H}_{2} \mathrm{O}$ or $\mathrm{ZnO}$.

As is well-known, well-developed alumina nanostructures, such as $\mathrm{AlOOH}$ or $\mathrm{Al}_{2} \mathrm{O}_{3}$, can only be obtained at higher reaction temperatures by hydrothermal synthesis ${ }^{52}$ or solvothermal synthesis. ${ }^{53}$ Thus, in the present reaction system, it is impossible for the alumina crystals to develop well because of the low reaction temperature of $50{ }^{\circ} \mathrm{C}$.

$\mathrm{Zn}_{6} \mathrm{Al}_{2}(\mathrm{OH})_{16}\left(\mathrm{CO}_{3}\right) \cdot 4 \mathrm{H}_{2} \mathrm{O}$, known as a layered double hydroxide (LDHs) or hydrotalcite-like compound, exists either as a natural mineral or a synthesized material. It has a sandwich structure composed of a cation $\left(\mathrm{Zn}^{2+}\right.$ and $\left.\mathrm{Al}^{3+}\right)$ layer (octahedron) and an anion $\left(\mathrm{CO}_{3}{ }^{2-}\right)$ interlayer, both of which are quite tunable (Scheme S1 in the ESI $\uparrow$ ). ${ }^{54,55}$ Considering its structural characteristics, in the present reaction system, the crystal growth of $\mathrm{Zn}_{6} \mathrm{Al}_{2}(\mathrm{OH})_{16}\left(\mathrm{CO}_{3}\right) \cdot 4 \mathrm{H}_{2} \mathrm{O}$ is a dominant factor in the formation of well-developed 2D flake-like nanostructures via the recrystallization process of the mixed crystals obtained after ion-exchange reactions. According to the abovementioned discussions, we believe that the ionic liquid molecules adsorbed on the surface of the $\mathrm{Zn}_{6} \mathrm{Al}_{2}(\mathrm{OH})_{16}\left(\mathrm{CO}_{3}\right) \cdot 4 \mathrm{H}_{2} \mathrm{O}$ crystallites play an important role as templates or structural indicators; however, they also adsorb on the surface of the $\mathrm{Al}_{2} \mathrm{O}_{3} \cdot 3 \mathrm{H}_{2} \mathrm{O}$ crystallites. Since the $\mathrm{pH}$ value of the present reaction system is about 7 and the PZCs of $\mathrm{Zn}_{6} \mathrm{Al}_{2}(\mathrm{OH})_{16}\left(\mathrm{CO}_{3}\right) \cdot 4 \mathrm{H}_{2} \mathrm{O}$ and $\mathrm{Al}_{2} \mathrm{O}_{3^{-}}$ $\cdot 3 \mathrm{H}_{2} \mathrm{O}$ crystals are about 11.5 and 9.7, ${ }^{56,57}$ respectively, the surfaces of the abovementioned two kinds of crystallites are positively charged. Therefore, the ionic liquid molecules adsorb on the surfaces of the crystals through an anionic dominant model. ${ }^{39}$ The schematic of adsorption is shown in Scheme 1.

To investigate the formation process of the flake-like $\mathrm{ZnAl}_{2} \mathrm{O}_{4}$ nanostructures, we carried out analogous experiments for different reaction durations, as shown in Fig. 6 .

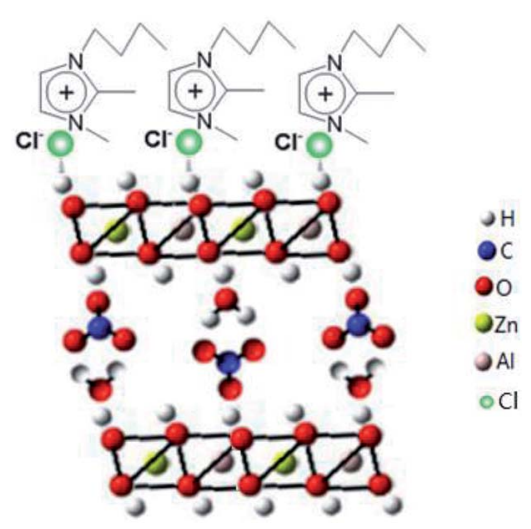

Scheme 1 Schematic for the adsorption of [bdmim] Cl molecules on the surface of the $\mathrm{Zn}_{6} \mathrm{Al}_{2}(\mathrm{OH})_{16}\left(\mathrm{CO}_{3}\right) \cdot 4 \mathrm{H}_{2} \mathrm{O}$ crystallite. 

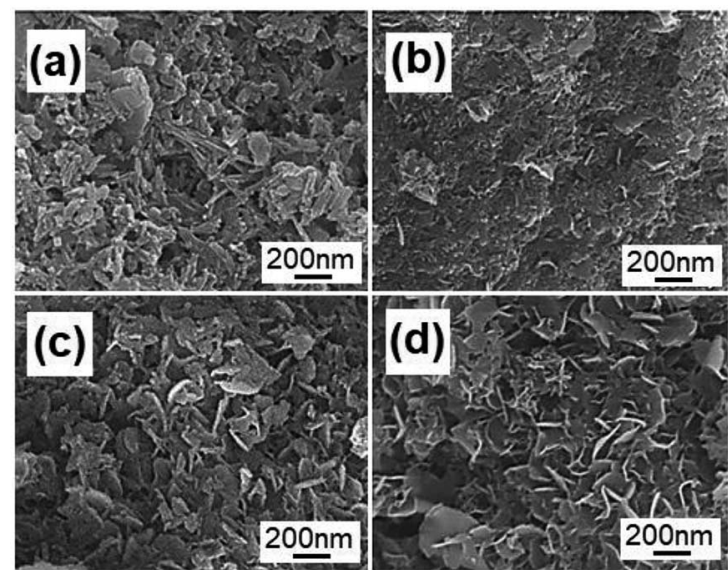

Fig. 6 FE-SEM images of the products obtained by ion exchange from $\mathrm{Na}-\mathrm{Dw}$ at $50{ }^{\circ} \mathrm{C}$ for (a) $1 \mathrm{~h}$, (b) $2 \mathrm{~h}$, (c) $4 \mathrm{~h}$ and (d) $8 \mathrm{~h}$.

Fig. 6a shows that irregular particles are first formed after reaction for $1 \mathrm{~h}$ at $50{ }^{\circ} \mathrm{C}$. The morphology of these particles is entirely different from that of the Na-Dw parent material; this indicates that the ion-exchange process is accompanied by the dissolution of precursor molecules rather than simple in situ ion exchange. When the reaction time was extended to $2 \mathrm{~h}$, some nanoflake-like structures appeared (Fig. 6b). Large-scale underdeveloped nanoflakes were formed after a $4 \mathrm{~h}$ reaction (Fig. 6c), and well-developed nanoflake-like structures could be obtained after an $8 \mathrm{~h}$ reaction (Fig. 6d). Moreover, there was no significant change in the morphology after a $10 \mathrm{~h}$ reaction.

Based on the abovementioned experimental results, a possible formation process of the flake-like $\mathrm{ZnAl}_{2} \mathrm{O}_{4}$ was proposed. In the first stage, irregular particles were formed via dissolution of the Na-Dw parent material, which underwent ion exchange with $\mathrm{Zn}^{2+}$ ions and reprecipitated in sequence, as shown in Scheme 2. In the subsequent stage, the dissolutionrecrystallization process dominated, and the $[\mathrm{bdmim}][\mathrm{Cl}]$ molecules adsorbed on the surface of the irregular particles as a soft template to control the direction of the crystal growth, as illustrated in Scheme 1. Herein, the $\mathrm{Cl}^{-}$ions from [bdmim] $\mathrm{Cl}$ preferentially adsorbed on the building blocks of hydrotalcitelike $\mathrm{Zn}_{6} \mathrm{Al}_{2}(\mathrm{OH})_{16}\left(\mathrm{CO}_{3}\right) \cdot 4 \mathrm{H}_{2} \mathrm{O}$ due to the formation of hydrogen bonds between $\mathrm{Cl}^{-}$ions and $\mathrm{Zn}_{6} \mathrm{Al}_{2}(\mathrm{OH})_{16}\left(\mathrm{CO}_{3}\right) \cdot 4 \mathrm{H}_{2} \mathrm{O}$ molecules; then, the $[\mathrm{bdmim}]^{+}$ions also adsorbed on the abovementioned building blocks due to electrostatic interactions. As previously reported, the $[\mathrm{bdmim}]^{+}$ions have a great
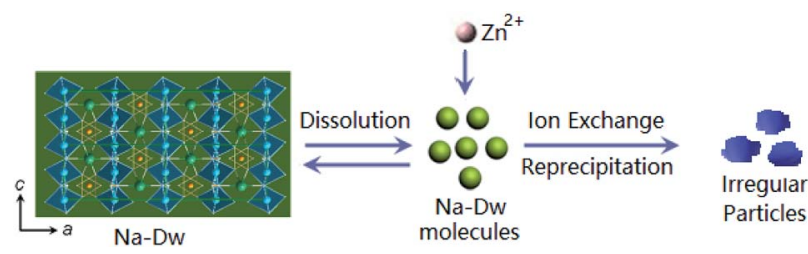

Scheme 2 Schematic for the ion-exchange process and the reprecipitation process occurring in the present reaction system by the addition of zinc salt. tendency to self-assemble into ordered structures that are stabilized by additional $\pi-\pi$ interactions along the aligned hydrogen bonds. ${ }^{40}$ In the last stage, an Ostwald ripening process dominates, and consequently, well-developed 2D flake-like nanostructures are obtained. Based on the abovementioned discussions, we proposed the formation mechanism of the mesoporous $\mathrm{ZnAl}_{2} \mathrm{O}_{4}$ spinel nanoflakes, as illustrated in Scheme 3.

To investigate the specific surface area and porous nature of the $\mathrm{ZnAl}_{2} \mathrm{O}_{4}$ spinel nanoflakes, Brunauer-Emmett-Teller (BET) gas-sorption measurements were carried out. The nitrogen adsorption/desorption isotherm obtained for the product shows significant hysteresis at the relative pressure $P / P_{0}$ of above 0.71 (Fig. 7). Moreover, the BET specific surface area of the product was calculated, which was about $245 \mathrm{~m}^{2} \mathrm{~g}^{-1}$, higher than the previous research results: $183.5 \mathrm{~m}^{2} \mathrm{~g}^{-1},{ }_{18} 182.8 \mathrm{~m}^{2} \mathrm{~g}^{-1}$ (ref. 45) and $147 \mathrm{~m}^{2} \mathrm{~g}^{-1} .^{58}$ The Barrett-Joyner-Halenda (BJH) calculations for the pore-size distribution, derived from the desorption data, reveal a narrow pore distribution with one apex centered at $14.5 \mathrm{~nm}$ (inset of Fig. 7), indicating that the asobtained $\mathrm{ZnAl}_{2} \mathrm{O}_{4}$ spinel product has mesopores. These mesopores presumably arise from the spaces between adjacent

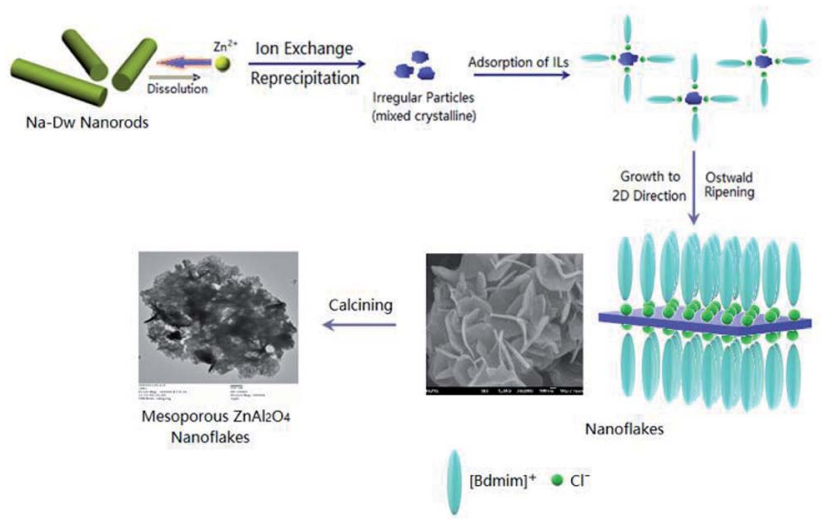

Scheme 3 Schematic for the formation of the mesoporous $\mathrm{ZnAl}_{2} \mathrm{O}_{4}$ spinel nanoflakes.

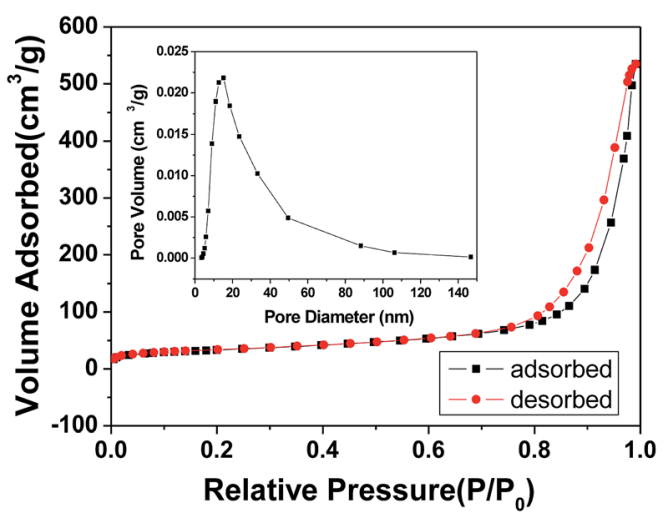

Fig. $7 \quad \mathrm{~N}_{2}$ adsorption-desorption isotherm and the pore-size distribution curve (inset) for the $\mathrm{ZnAl}_{2} \mathrm{O}_{4}$ spinel nanoflakes obtained by calcination at $700{ }^{\circ} \mathrm{C}$ for $2 \mathrm{~h}$. 
nanoparticles formed during the calcination process due to the release of $\mathrm{CO}_{2}$ and $\mathrm{H}_{2} \mathrm{O}$ molecules from $\mathrm{Zn}_{6} \mathrm{Al}_{2}(\mathrm{OH})_{16}\left(\mathrm{CO}_{3}\right)$. $4 \mathrm{H}_{2} \mathrm{O}$.

\section{Conclusions}

In summary, the well-developed mesoporous $\mathrm{ZnAl}_{2} \mathrm{O}_{4}$ spinel nanoflakes were successfully prepared by the ion-exchange method using an aqueous solution of $\mathrm{Zn}\left(\mathrm{NO}_{3}\right)_{2}$ and $\mathrm{Na}$-Dw parent materials in the presence of an ionic liquid, [bdmim] $[\mathrm{Cl}]$, at $50{ }^{\circ} \mathrm{C}$, followed by calcination at $700{ }^{\circ} \mathrm{C}$ for $2 \mathrm{~h}$. The formation mechanism of the $\mathrm{ZnAl}_{2} \mathrm{O}_{4}$ nanoflakes was explored on the basis of control experiments and structure analyses. The results demonstrate that $[\mathrm{bdmim}][\mathrm{Cl}]$ plays a crucial role in the formation of the flake-like morphology at the abovementioned low temperature. The optimal mole ratio of $\mathrm{Zn}^{2+}: \mathrm{Na}-\mathrm{Dw}$ is $1: 2$ to obtain the $\mathrm{ZnAl}_{2} \mathrm{O}_{4}$ spinel nanoflakes. The BET-specific surface area of the mesoporous $\mathrm{ZnAl}_{2} \mathrm{O}_{4}$ nanoflakes, constructed by numerous nanoparticles, is as high as $245 \mathrm{~m}^{2} \mathrm{~g}^{-1}$. Since Na-Dw is a cheap natural mineral, the synthesis of $\mathrm{ZnAl}_{2} \mathrm{O}_{4}$ spinel nanostructures at low temperatures using Na$\mathrm{Dw}$ as a parent material can be applied as an economical and significant industrial method. The mesoporous $\mathrm{ZnAl}_{2} \mathrm{O}_{4}$ spinel nanoflakes are expected to be used in some applications such as in catalysts and catalyst supports.

\section{Conflicts of interest}

There are no conflicts to declare.

\section{Acknowledgements}

This work was supported by the National Natural Science Foundation of China (Grant No. 20971070 and 21073095), the 111project (B12015) and the National Foundation of Science and Technology (2017012012) of DPRK.

\section{References}

1 S. K. Sampath and J. F. Cordaro, J. Am. Ceram. Soc., 1998, 81, 649.

2 R. Roesky, J. Weiguny, H. Bestgen and U. Dingerdissen, Appl. Catal., A, 1999, 176, 213.

3 C. G. Anchieta, D. Sallet, E. L. Foletto, S. S. Da Silva, O. Chiavone-Filho and C. A. do Nascimento, Ceram. Int., 2014, 40, 4173.

4 S. Battidton, C. Rigo, E. Cruz Severo, M. A. Mazutti, R. C. Kuhn, A. Gundel and E. L. Foletto, Mater. Res., 2014, 17, 735.

5 M. Garcia-Hipolito, J. Guzman-Mendoza, E. Martinez, O. Alvarez-Fregoso and C. Falcony, Phys. Status Solidi A, 2004, 201, 1510.

6 N. J. Van der Laag, M. D. Snel, P. C. M. M. Magusin and G. De With, J. Eur. Ceram. Soc., 2004, 24, 2417.

7 S. Mathur, M. Veith, M. Haas, A. Shen, N. Lecerf, V. Huch, S. Hufner, R. Haberkorn, H. P. Beck and M. Jilavi, J. Am. Ceram. Soc., 2001, 84, 1921.
8 H. Matsui, C. Xu and H. Tateyama, Appl. Phys. Lett., 2001, 78, 1068.

9 D. L. Ge, Y. J. Fan, C. L. Qi and Z. X. Sun, J. Mater. Chem. A, 2013, 1, 1651.

10 S. Pin, M. Suardelli, F. D'Acapito, G. Spinolo, M. Zema, S. C. Tarantino, L. Barba and P. Ghigna, J. Phys. Chem. C, 2013, 117, 6113.

11 A. D. Ballarini, S. A. Bocanegra, A. C. Castro, S. R. Miguel and O. A. Scelza, Catal. Lett., 2009, 129, 293.

12 E. L. Foletto, S. Battiston, J. M. Simões, M. M. Bassaco, L. S. Pereira, E. M. Flores and E. I. Müller, Microporous Mesoporous Mater., 2012, 163, 29.

13 F. Davar and M. Salavati-Niasari, J. Alloys Compd., 2011, 509, 2487.

14 A. V. Belyaev, I. I. Evdokimov, V. V. Drobotenko and A. A. Sorokin, J. Eur. Ceram. Soc., 2017, 37, 2747.

15 S. G. Menon, K. S. Choudhari, S. A. Shivashankar, S. Chidangila and S. D. Kulkarni, New J. Chem., 2017, 41, 5420.

16 D. Zhang, Y. H. Qiu, Y. R. Xie, X. C. Zhou, Q. R. Wang, Q. Shi, S. H. Li and W. J. Wang, Mater. Des., 2017, 115, 37.

17 S. Sommer, E. D. Bøjesen, A. B. Blichfeld and B. B. Iversen, J. Solid State Chem., 2017, 256, 45.

18 H. P. Macedo, R. L. Medeiros, A. L. Medeiros, A. A. S. Oliveira, G. P. Figueredo, M. A. Melo and D. M. Melo, Mater. Res., 2017, 20, 29.

19 Z. Li, S. Zhang and W. Lee, J. Eur. Ceram. Soc., 2007, 27, 3407. 20 M. Obaidullaha, T. Furusawa, I. A. Siddiquey, M. Sato and N. Suzuki, Adv. Powder Technol., 2017, 28, 2678.

21 C. S. Lei, M. Pi, W. Zhou, Y. Q. Guo, F. Zhang and J. Q. Qin, Chem. Phys. Lett., 2017, 687, 143.

22 L. B. Railsback, Carbonates Evaporites, 1999, 14, 1.

23 C. J. Serna, J. L. White and S. L. Hem, J. Pharm. Sci., 1978, 67, 324.

24 P. V. Bonsignore, Plast. Eng., 1976, 32, 41.

25 E. A. Woycheshin, R. J. Rigge and I. Sobolev, US Pat. 3878 166, 1975.

26 R. L. Altman, L. A. Mayer and A. C. Ling, US Pat. 4406 797, 1983.

27 G. Gillman and A. Noble, Environ. Qual. Manag., 2005, 15, 59. 28 G. Ci. Li, Y. Q. Liu, L. L. Guan, X. F. Hu and C. G. Liu, Mater. Res. Bull., 2012, 47, 1073.

29 M. Shoaib, M. Mazhar, A. Mushtaq, A. Jamil, T. T. Muhammad, A. Izhar and M. H. Syed, Mater. Chem. Phys., 2017, 191, 62.

30 X. X. Zou, P. Wang, Z. Wang, G. Fan, S. Chen, S. Liao, H. Si and M. Lu, Ceram. Int., 2018, 44, 10847.

31 I. B. Malham, P. Letellier and M. Turmine, J. Phys. Chem. B, 2006, 110, 14212.

32 X. C. Duan, J. M. Ma, Y. Shen and W. J. Zheng, Inorg. Chem., 2012, 51, 914.

33 T. L. Greaves and C. J. Drummond, Chem. Soc. Rev., 2013, 42, 1096.

34 L. Xu, J. Xia, L. Wang, J. Qian, H. Li, K. Wang, K. Sun and M. He, Chem.-Eur. J., 2014, 20, 2244.

35 R. Hayes, G. G. Warr and R. Atkin, Chem. Rev., 2015, 115, 6357. 
36 X. C. Duan, H. Huang, S. H. Xiao, J. W. Deng, G. Zhou, Q. H. Lia and T. H. Wang, J. Mater. Chem. A, 2016, 4, 8402.

37 H. Roohi, H. Iloukhani and F. Rouhani, J. Mol. Liq., 2017, 240, 138.

38 X. C. Duan, T. I. Kim, D. Li, J. Ma and W. J. Zheng, Chem.Eur. J., 2013, 19, 5924.

39 J. Zhang, H. J. Feng, J. Q. Yang, Q. Qin, H. M. Fan, C. Y. Wei and W. J. Zheng, ACS Appl. Mater. Interfaces, 2015, 7, 21735.

40 Q. Qin, T. I. Kim, X. C. Duan, J. B. Lian and W. J. Zheng, Cryst. Growth Des., 2016, 16, 6139.

41 W. H. Luo, G. F. Zhang, Y. X. Cui, Y. Sun, Q. Qin, J. Zhang and W. J. Zheng, J. Mater. Chem. A, 2017, 5, 11278.

42 Q. Qin, J. Hao and W. J. Zheng, ACS Appl. Mater. Interfaces, 2018, 10, 17827.

43 X. C. Duan, T. I. Kim, L. L. Han, J. M. Ma, X. W. Du and W. J. Zheng, Sci. Rep., 2013, 3, 3218.

44 B. D. Cullity and S. R. Stock, Elements of X-Ray Diffraction, Pearson, London, 3rd edn, 2014, p. 664.

45 X. L. Du, L. Q. Li, W. X. Zhang, W. C. Chen and Y. T. Cui, Mater. Res. Bull., 2015, 61, 64.

46 M. Mokhtar, A. Inayat, J. Ofili and W. Schwieger, Appl. Clay Sci., 2010, 50, 176.
47 A. Smalenskaitea, D. E. L. Vieirab, A. N. Salakb, M. G. S. Ferreirab, A. Katelnikovasc and A. Kareiva, Appl. Clay Sci., 2017, 143, 175.

48 C. R. Chen, P. X. Ding, S. Xu, J. Z. Du, H. Y. Zeng and Y. X. Sun, Appl. Clay Sci., 2018, 161, 404.

49 Y. Y. Zhang, J. Chang, J. Y. Zhao and Y. F. Fang, J. Am. Ceram. Soc., 2018, 101, 4262.

50 M. Barroso, M. Gomez, G. J. Andrade, L. Arrua and M. Abello, J. Phys. Chem. Solids, 2006, 67, 1583.

51 X. Z. Guo, P. A. Yin, W. Lei and H. Yang, New J. Chem., 2017, 41, 11998.

52 J. K. Lee, E. J. Jang, H. Y. Jeong and J. H. Kwak, Appl. Catal., A, 2018, 556, 121.

53 J. B. Lian, J. M. Ma, X. C. Duan, T. I. Kim, H. B. Li and W. J. Zheng, Chem. Commun., 2010, 46, 2650.

54 M. Shamim and K. Dana, J. Mol. Struct., 2016, 1125, 27.

55 M. Zhou, L. Yan, H. Ling, Y. P. Diao, X. L. Pang, Y. Wang and K. Gao, Appl. Surf. Sci., 2017, 404, 246.

56 W. Cai, J. Yu and M. Jaroniec, J. Mater. Chem., 2010, 20, 4587. 57 R. Rojas Delgado, C. P. De Pauli, C. Barriga Carrasco and M. J. Avena, Appl. Clay Sci., 2008, 40, 27.

58 T. R. Mandlimath and K. I. Sathiyanarayanan, RSC Adv., 2016, 6, 3117. 